\title{
Telomere shortening occurs in Asian Indian Type 2 diabetic patients
}

\author{
A. Adaikalakoteswari, M. Balasubramanyam and V. Mohan
}

Department of Cell and Molecular Biology, Madras Diabetes Research Foundation, Chennai, India

Accepted 27 October 2004

\begin{abstract}
Aim Telomere shortening has been reported in several diseases including atherosclerosis and Type 1 diabetes. Asian Indians have an increased predilection for Type 2 diabetes and premature coronary artery disease. The aim of this study was to determine whether telomeric shortening occurs in Asian Indian Type 2 diabetic patients.
\end{abstract}

Methods Using Southern-blot analysis we determined mean terminal restriction fragment (TRF) length, a measure of average telomere size, in leucocyte DNA. Type 2 diabetic patients without any diabetes-related complications $(n=40)$ and age- and sex-matched control non-diabetic subjects $(n=40)$ were selected from the Chennai Urban Rural Epidemiology Study (CURES). Plasma level of malondialdehyde (MDA), a marker of lipid peroxidation, was measured by TBARS (thiobarbituric acid reactive substances) using a fluorescence method.

Results Mean $( \pm$ SE) TRF lengths of the Type 2 diabetic patients $(6.01 \pm 0.2 \mathrm{~kb})$ were significantly shorter than those of the control subjects $(9.11 \pm 0.6 \mathrm{~kb})(P=$ 0.0001). Among the biochemical parameters, only levels of TBARS showed a negative correlation with shortened telomeres in the diabetic subjects $(r=-0.36$; $P=0.02$ ). However, telomere lengths were negatively correlated with insulin resistance (HOMA-IR) $(r=-0.4 ; P=0.01)$ and age $(r=-0.3 ; P=0.058)$ and positively correlated with HDL levels $(r=0.4 ; P=0.01)$ in the control subjects. Multiple linear regression (MLR) analysis revealed diabetes to be significantly $(P<0.0001)$ associated with shortening of TRF lengths.

Conclusions Telomere shortening occurs in Asian Indian Type 2 diabetic patients.

Diabet. Med. 22, 1151-1156 (2005)

Keywords Telomere, diabetes mellitus, oxidative stress, senescence, Asian Indians

\section{Introduction}

Telomeres, the TTAGGG tandem repeats at the ends of mammalian chromosomes, undergo attrition with each division of somatic cells in culture, and hence their length is an indicator of the replicative potential of these cells [1]. The inability of DNA polymerases to replicate a linear DNA molecule to its very end [2] and the action of a strand-specific exonuclease [3] are believed to contribute to the shortening of telomeres. Increased oxygen tension has also been shown to accelerate

Correspondence to: Dr M. Balasubramanyam, Department of Cell and Molecular Biology, Madras Diabetes Research Foundation, 4, Conran Smith Road, Gopalapuram, Chennai-600 086, India. E-mail: drbalu@mvdsc.org telomere shortening in replicating fibroblasts in vitro [4]. Telomeric DNA sequences appear to be particularly prone to chromosomal breakage [5], and their GGG-triplets are a major target for reactive oxygen species [6-8].

Recent studies have demonstrated that telomere shortening is related to various pathological conditions including atherosclerosis [9-12]. Jeanclos et al. [13] established an association between telomere shortening in white blood cells (WBCs) and Type 1, but not in Type 2, diabetic patients of European origin. Asian Indian Type 2 diabetic patients differ from Europeans in several aspects: the onset of diabetes occurs at a younger age [14], and there is a greater degree of hyperinsulinaemia [15] and insulin resistance [16]. In addition they have very high prevalence rates of premature coronary artery disease $[17,18]$. 
In this paper we report that telomere lengths are shortened in urban southern Indian Type 2 diabetic patients. This is the first report, to our knowledge, of telomere shortening in Type 2 diabetes.

\section{Subjects and methods}

\section{Sample selection}

The Chennai Urban Rural Epidemiology Study (CURES) is an ongoing epidemiological study conducted on a representative population of Chennai (formerly Madras), the fourth largest city in India with a population of approximately 4.2 million. The methodology of the study has been published elsewhere $[19,20]$. Briefly, in Phase 1 of the urban component of CURES, 26001 individuals were recruited based on a systematic random sampling technique. Self-reported diabetic subjects were classified as 'known diabetic subjects'.

In Phase 2 of CURES, all known diabetic subjects $(n=1529)$ were invited to our centre for detailed studies on vascular complications. In addition, age- and sex-matched non-diabetic subjects underwent oral glucose tolerance tests (OGTT) using $75 \mathrm{~g}$ of glucose load. Those who were confirmed by OGTT to have fasting venous plasma glucose $<6.1 \mathrm{mmol} / \mathrm{l}$ and a $2-\mathrm{h}$ plasma glucose value $<7.8 \mathrm{mmol} / 1$ were categorized as normal glucose tolerance (NGT). For the present study we randomly selected 40 diabetic subjects without any complications (using computer-generated random numbers) and 40 age- and sexmatched subjects with NGT. The study had a power of $80 \%$ to detect a statistically significant $(P=0.05)$ difference of $2.0 \mathrm{~kb}$ in TRF between the two study groups.

Physical examination included height, weight, waist and hip measurements using standardized techniques. Blood pressure was recorded in the right arm with a mercury sphygmomanometer (Diamond Deluxe Blood Pressure Apparatus, Pune, India) while the patients were seated. Two readings were taken $5 \mathrm{~min}$ apart and the mean of the two was taken as the blood pressure. A fasting blood sample was taken, and serum separated and stored at $-70^{\circ} \mathrm{C}$ until the assays were performed. Biochemical analyses were carried out on a Hitachi-912 Autoanalyser (Hitachi, Mannheim, Germany) using kits supplied by Roche Diagnostics (Mannheim, Germany). Fasting plasma glucose (GOD-POD method), serum cholesterol (CHOD-PAP method), serum triglycerides (GPO-PAP method) and HDL cholesterol (direct method-polyethylene glycol-pretreated enzymes) were measured. Low-density lipoprotein (LDL) cholesterol was calculated using the Friedewald formula [21]. Glycated haemoglobin $\left(\mathrm{HbA}_{1 \mathrm{c}}\right)$ was estimated by high-pressure liquid chromatography using the Variant machine (Bio-Rad, Hercules, CA, USA). Serum insulin concentration was estimated using Dako kits (Dako, Glostrup, Denmark). Insulin resistance (HOMA-IR) was calculated using the Homeostasis Model Assessment using the formula: fasting insulin $(\mu \mathrm{IU} / \mathrm{ml}) \times$ fasting glucose $(\mathrm{mmol} / \mathrm{l}) / 22.5$ [22] Informed consent was obtained from all study subjects, and the study was approved by the institutional Ethics Committee.

To avoid the confounding effect of diabetic complications on telomeric shortening, the diabetic subjects selected had no evidence of retinopathy (assessed by retinal photography) or nephropathy (24-h protein excretion $<100 \mathrm{mg} /$ day and urinary albumin levels $<30 \mu \mathrm{g} / \mathrm{mg}$ creatinine). They also had no history of angina or myocardial infarction, and a normal 12-lead resting ECG. Hypertension was diagnosed if the subjects had been treated with antihypertensive drugs or had systolic blood pressure (SBP) $\geq 140 \mathrm{mmHg}$ or diastolic blood pressure (DBP) $\geq 90 \mathrm{mmHg}$.

\section{TRF length analysis}

Genomic DNA was prepared from whole blood by digestion with proteinase-K and extraction with phenol/chloroform and was quantified spectrophotometrically. The DNA samples extracted from WBCs were coded, and only after completion of the TRF measurement was the code broken for data analysis. Terminal restriction fragment (TRF) lengths were measured using the Southern-blotting technique [13]. Briefly, equal amounts of DNA $(2 \mu \mathrm{g})$ were digested with restriction enzymes HinfI (20 U) and RsaI (20 U) (Roche Diagnostics) for $2 \mathrm{~h}$ at $37^{\circ} \mathrm{C}$ to liberate TRFs, which include both subtelomeric repetitive DNA and telomeric TTAGGG repeats. The TRFs that determines the telomere lengths were separated by electrophoresis on $0.8 \%$ agarose gel denatured with $0.5 \mathrm{M} \mathrm{NaOH} / 1.5 \mathrm{M} \mathrm{NaCl}$ and neutralized for $30 \mathrm{~min}$ in $0.5 \mathrm{M}$ Tris and $1.5 \mathrm{M} \mathrm{NaCl}$. The DNA was transferred overnight to a nylon membrane positively charged using capillary transfer. The membranes were then hybridized with telomeric probe digoxigenin 3 'end labelled $5^{\prime}-(\text { CCCTAA })_{3}$ for $3 \mathrm{~h}$ in the hybridization solution. They were then washed at room temperature, three times in $2 \times$ saline sodium citrate (SSC), $0.1 \%$ SDS each for $15 \mathrm{~min}$ and once in $2 \times \mathrm{SSC}$ for $15 \mathrm{~min}$. The digoxigenin-labelled probe was detected by the digoxigenin luminescent detection procedure and exposed on $\mathrm{X}$-ray film. The mean TRF length was determined using automated BIORAD Gel documentation software and calculated as follows: TRF $=\Sigma \mathrm{ODi} /(\Sigma \mathrm{ODi} / \Sigma \mathrm{MWi})$, where ODi is the optical density at a given position in the lane and MWi is the molecular weight at that position; this formula [23] accounts for the fact that longer telomeres bind more labelled probes and consequently appear darker on the X-ray film (Fig. 1). Proper reference standards and molecular-weight markers were included in all blots. To show the reproducibility of our method, we measured the telomere lengths of eight subjects on two different occasions. For this, blood samples were taken twice from the same subject on two different occasions and the respective DNA used for the TRF length measurements were referred to as TRF1 and TRF2. As shown in Fig. 2, the two values correlated well $(r=0.93 ; P<0.001)$, indicating that white blood cell mean TRF length is a reproducible measure. The interassay coefficient of variation was $<3 \%$ and the maximum difference between the two blots carried out from the same subject on different days (blot-to-blot variability) was $<7 \%$, i.e. $<0.5 \mathrm{~kb}$.

\section{Lipid peroxidation}

Plasma levels of malondialdehyde (MDA), a marker of lipid peroxidation, were measured by TBARS (thiobarbituric acid reactive substances) by fluorescence methodology [24]. Plasma $(200 \mu \mathrm{l})$ was treated with $8.1 \%$ SDS and $20 \%$ acetic acid to solubilize and precipitate protein and then heated with TBA for $1 \mathrm{~h}$ at $95^{\circ} \mathrm{C}$. The supernatant was then extracted with butanol:pyridine $(15: 1)$, to produce a fluorescent product, which 


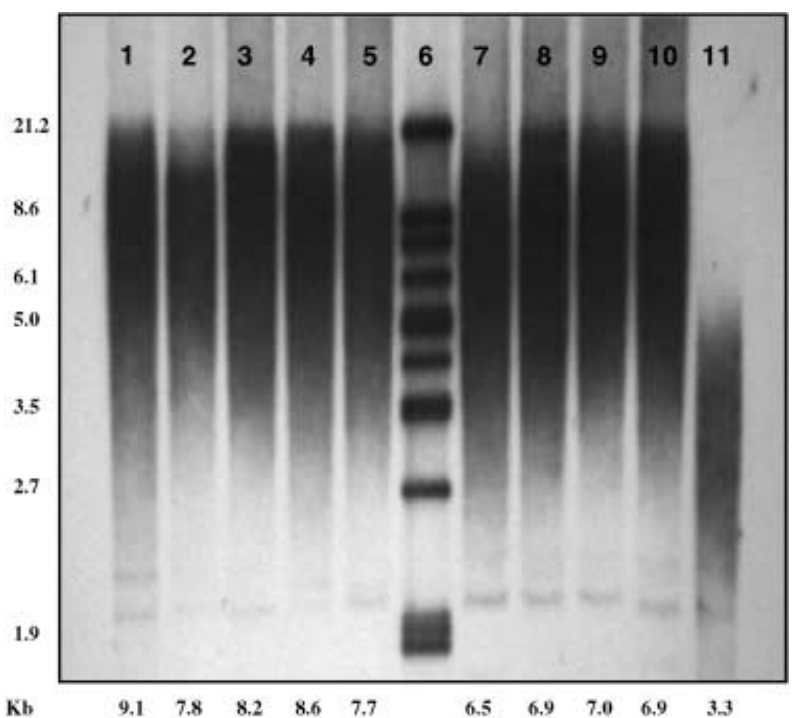

Figure 1 Autoradiograph showing the lengths of the terminal restriction fragment (TRF) of genomic DNA from white blood cells (WBCs). Lanes 2-5: samples from the control subjects. Lanes 7-10: samples from the diabetic subjects; Lanes 1 \& 11: reference samples (High MWt \& Low MWt); Lane 6: molecular weight marker (1.9-21.2 Kb).

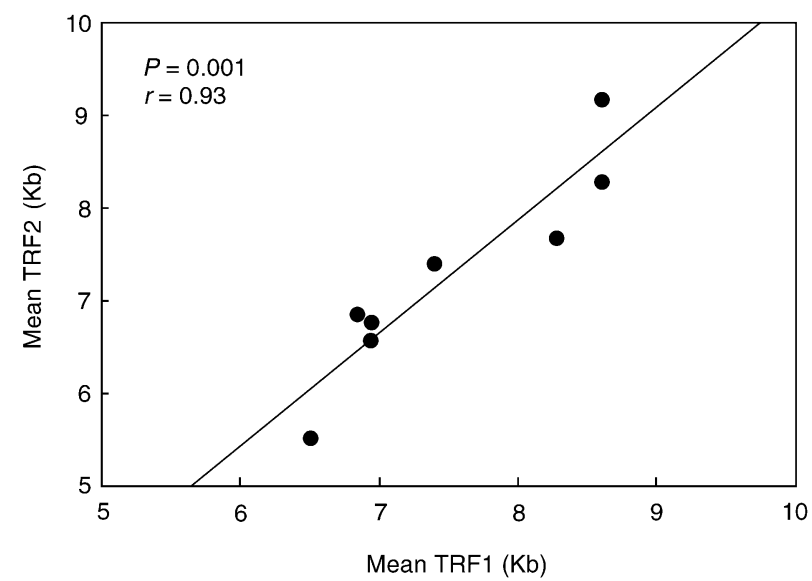

Figure 2 Reproducibility of mean telomere restriction fragment (TRF) length assay. Blood samples were taken twice from the same subject on two different occasions and the respective DNA was used for the determination of telomere lengths (referred as TRF1 and TRF2). Excellent correlation $(r=0.93 ; P=0.001)$ between these two measurements obtained from eight individuals.

was detected by excitation at $535 \mathrm{~nm}$ and emission at $553 \mathrm{~nm}$. Absolute MDA (malonodialdehyde) levels were calculated using the regression parameters obtained using various concentrations $(0.25-5.0 \mathrm{nM})$ of the standard, $1,1^{\prime}, 3,3^{\prime}$, -tetramethoxypropane. Inter- and intra-assay coefficients of variation of the above method were $<5$ and $10 \%$, respectively.

\section{Statistical analysis}

Comparisons between groups were performed using an unpaired Student's $t$-test. Two-tailed $P$-values equal to or less than
0.05 were considered statistically significant. Pearson correlation analysis was performed between variables. Risk variables that had a significant association with TRF on univariate regression were included as independent variables in multiple linear regression analysis. Care was taken to avoid intercorrelated variables in the regression equation. All analyses were carried out using a Windows-based SPSS statistical package (Version 10.0, Chicago, IL, USA).

\section{Results}

Table 1 shows the characteristics of both the diabetic and nondiabetic subjects. None of the diabetic patients had ketonuria or any history of diabetic ketosis at any time and all were treated with oral agents sulphonylurea (glipizide or glibenclamide) and/ or metformin. Hence they all had Type 2 diabetes. Diabetic patients had significantly higher plasma glucose, $\mathrm{HbA}_{1 \mathrm{c}}$, serum cholesterol, triglycerides and HOMA-IR compared with the control subjects.

The mean $( \pm$ SE) TRF lengths were significantly lower in the patients with Type 2 diabetes $(6.01 \pm 0.2$; range 3.0-9.5 kb) compared with the control subjects $(9.11 \pm 0.6$; range $3.5-$ $15.8 \mathrm{~kb})(P=0.0001)$ (Fig. 3). Age-adjusted telomere lengths were significantly shorter in men $(7.69 \pm 0.6)$ than in women $(10.42 \pm 1.0)(P=0.02)$ in the control subjects. This gender difference in TRF length was not observed among the diabetic subjects (men $5.81 \pm 0.4$, women $6.22 \pm 0.3, P=0.51$ ). When compared with the diabetic subjects without hypertension $(6.74 \pm 0.3)$ the diabetic subjects with hypertension exhibited significantly shorter TRF lengths $(5.23 \pm 0.4)(P=0.007)$.

Lipid peroxidation as measured by TBARS was significantly higher in the patients with Type 2 diabetes $(9.69 \pm 1.0 \mathrm{nM} / \mathrm{ml})$ when compared with the control subjects $(6.17 \pm 0.3 \mathrm{nM} / \mathrm{ml})$ (Fig. 4a). Increased levels of TBARS also showed a negative correlation with shortened telomeres in the diabetic subjects $(r=-0.36 ; P=0.02)$ (Fig. 4b). However, such a relationship

Table 1 Clinical characteristics of the study subjects

\begin{tabular}{lcc}
\hline & $\begin{array}{c}\text { Control } \\
(n=40)\end{array}$ & $\begin{array}{c}\text { Type 2 diabetes } \\
(n=40)\end{array}$ \\
Parameters & $49 \pm 8$ & $49 \pm 7$ \\
\hline Age (years) & $20: 20$ & $20: 20$ \\
Male: Female $(n)$ & - & $3.3 \pm 2.8$ \\
Duration of diabetes (years) & $23.5 \pm 4.2$ & $25.2 \pm 3.8$ \\
Body mass index $\left(\mathrm{kg} / \mathrm{m}^{2}\right)$ & $4.7 \pm 0.8$ & $8.3 \pm 3.5^{*}$ \\
Fasting plasma glucose $(\mathrm{mmol} / \mathrm{l})$ & $5.5 \pm 0.6$ & $8.7 \pm 2.6^{*}$ \\
HbA $(\%)$ & $126 \pm 19$ & $125 \pm 25$ \\
Systolic blood pressure $(\mathrm{mmHg})$ & $77 \pm 11$ & $79 \pm 13$ \\
Diastolic blood pressure $(\mathrm{mmHg})$ & $4.6 \pm 0.8$ & $5.1 \pm 1.1^{*}$ \\
Serum Cholesterol $(\mathrm{mmol} / \mathrm{l})$ & $1.4 \pm 0.6$ & $2.1 \pm 1.1^{*}$ \\
Serum Triglycerides $(\mathrm{mmol} / \mathrm{l})$ & $1.08 \pm 0.3$ & $1.05 \pm 0.2$ \\
Serum HDL cholesterol $(\mathrm{mmol} / \mathrm{l})$ & $2.9 \pm 0.7$ & $3.1 \pm 0.9$ \\
Serum LDL cholesterol $(\mathrm{mmol} / \mathrm{l})$ & $1.75 \pm 1.1$ & $4.04 \pm 2.9^{*}$ \\
HOMA-IR & & \\
\hline
\end{tabular}

Values are expressed as mean \pm SD.

* $P<0.05$ compared with control. 


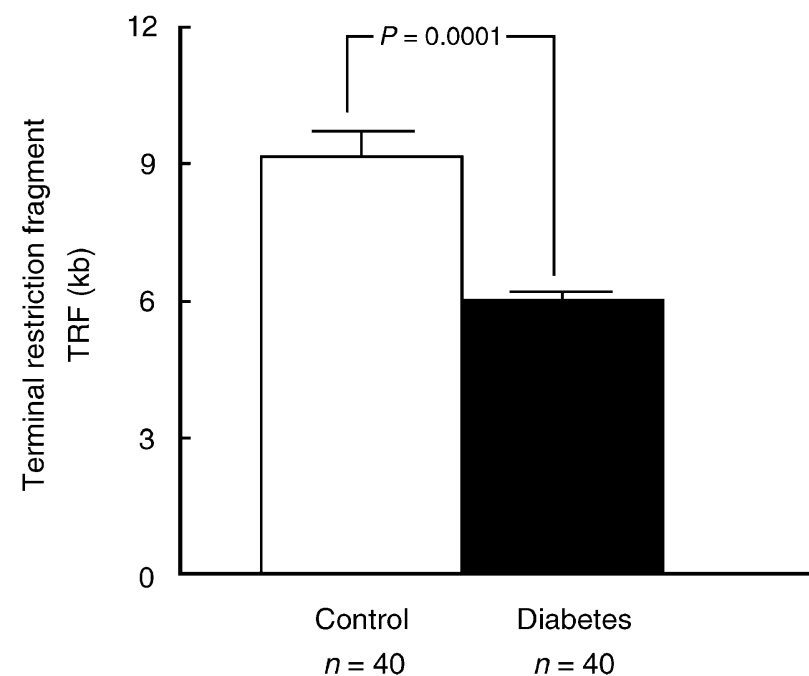

Figure 3 Mean $( \pm$ SE) telomere lengths of the control $(9.11 \pm 0.6 \mathrm{~kb})$ and Type 2 diabetic subjects $(6.01 \pm 0.2 \mathrm{~kb})$.

between TBARS and TRF was not observed in the control group.

Telomere lengths were negatively correlated with insulin resistance (HOMA-IR) $(r=-0.4 ; P=0.01)$ and age $(r=-0.3$; $P=0.058)$ and positively correlated with HDL levels $(r=0.4$; $P=0.01)$ in the control subjects. Correlation of TRF lengths with $\mathrm{HbA}_{1 \mathrm{c}}$ levels $(r=-0.28 ; P=0.01)$ and cholesterol to HDL ratio $(r=-0.31 ; P=0.005)$ was obvious only in the total study subjects. Multiple linear regression analysis carried out using diabetes status, cholesterol to HDL ratio and TBARS as independent variables revealed the presence of diabetes as the sole risk factor associated with telomere shortening $(\beta=-2.71$, $P<0.0001$ ).

\section{Discussion}

Shortening of telomeres has been reported to be present in patients with inherited respiratory chain disorders [25], Down's syndrome [26], vascular dementia [27] and ataxia-telangiectasia [28]. Recent studies have also shown that telomere shortening can be a biomarker of premature cell senescence in vascular diseases and metabolic disorders [10,11,12].

An earlier study from the USA demonstrated telomere shortening in Type 1, but not in Type 2 diabetic patients of European descent [13]. Our study is the first to demonstrate a shortened TRF length in WBCs in patients with Type 2 diabetes. It is possible that the increased insulin resistance observed in Asian Indians [16] contributes to the telomere shortening observed in our patients. This is supported by the association of the telomere shortening with HOMA-IR observed in this study. Our results also indicate the presence of diabetes as one of the risk factors associated with telomere shortening. It is possible that chronic hyperglycaemia and associated oxidative stress may modify TRF length in WBCs. Alternatively, a diminished TRF length could be a secondary phenomenon
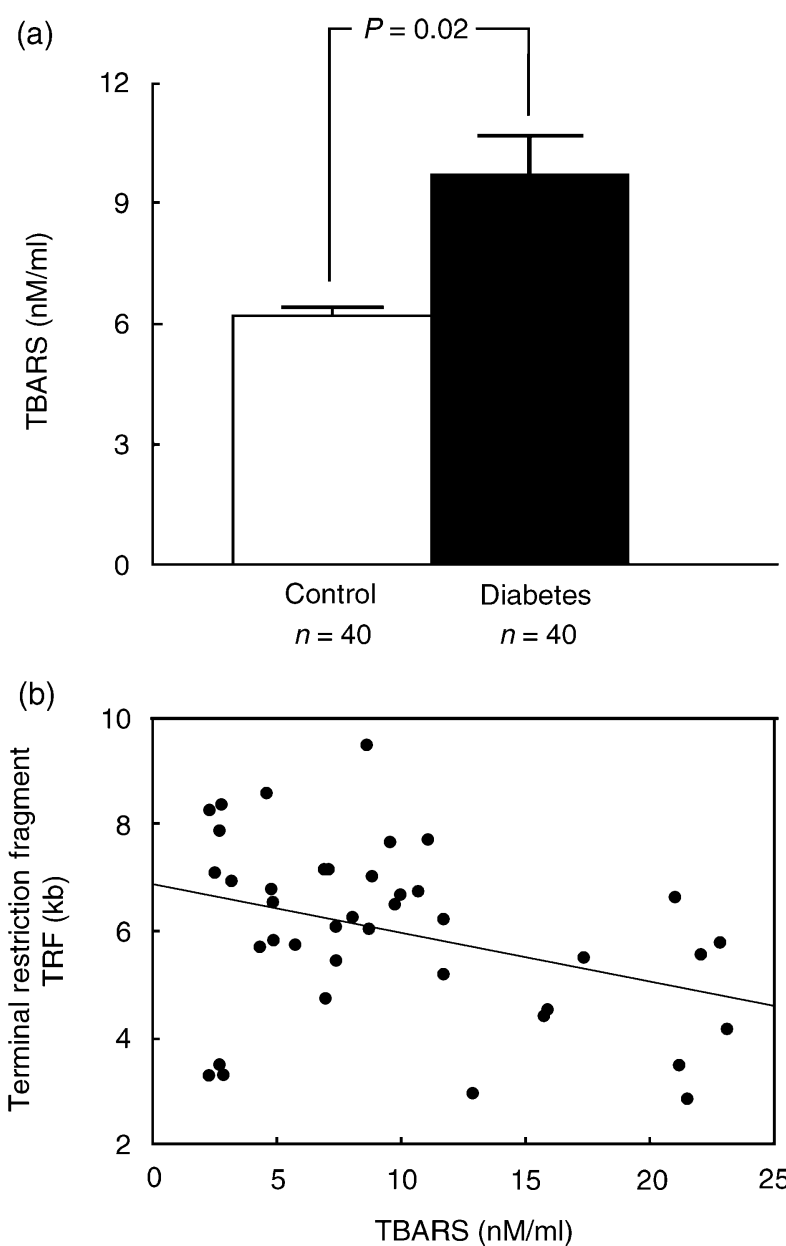

Figure 4 (a) Mean ( \pm SE) lipid peroxidation levels in the Type 2 diabetes $(9.69 \pm 1.0 \mathrm{nM} / \mathrm{ml})$ and control subjects $(6.17 \pm 0.3 \mathrm{nM} / \mathrm{ml})$. (b) Correlation between TBARS (thiobarbituric acid reactive substances) and terminal restriction fragment (TRF) length in the diabetic subjects $(r=-0.36 ; P=0.02)$.

arising out of accelerated telomere attrition owing to an increased turnover and chronic activation of inflammatory cells.

In non-diabetic subjects, the age-adjusted telomere length is shorter in men than in women, confirming earlier studies [2931]. As premenopausal women are less prone than men to cardiovascular diseases [32] and several systemic parameters show poor correlation with blood pressure in women [33], our observations suggest that the biology of ageing differs between men and women. Moreover, an oestrogen-responsive element is present in hTERT [34], and hence hormonal changes may influence telomerase to maintain the telomere length in women. However, this gender difference was absent in Type 2 diabetic subjects. It is well known that women with Type 2 diabetes lose their protection from coronary artery disease [35]. Our study confirms these findings using TRF as a marker.

Within the diabetic subjects, those with hypertension also showed a significantly reduced TRF length when compared with subjects without hypertension. Hypertensive subjects are 
at higher risk for atherosclerosis and accelerated cardiovascular ageing [30]. Increased oxidative stress has been considered as one of the molecular determinants of cardiovascular diseases [36]. Therefore telomere length may provide an additional link between oxidative stress and the predisposition to cardiovascular disease in hypertensive subjects.

The association of short telomeres with insulin resistance (as measured by HOMA-IR) and cholesterol to HDL ratio suggests that telomere shortening could probably be used as an additional marker of atherosclerosis. In support of this, coronary artery disease patients have been shown to exhibit telomere shortening [11]. Asian Indians have high prevalence rates of premature coronary artery disease [17,18,37]. The excess risk for coronary artery disease seen among Asian Indians has hitherto not been explained by any of the conventional risk factors. From this study one could speculate that telomere attrition could be one of the molecular mechanisms that predispose Asian Indian diabetic patients to premature coronary artery disease. However, further work needs to be performed on diabetic patients with and without coronary artery disease to confirm this hypothesis. It is also known that several additional factors such as oxygen-free radicals and elevated plasma homocysteine, which are overproduced in some metabolic diseases, are responsible for DNA damage and telomere shortening, and can induce atherosclerosis [8,38-40]. The positive association of HDL cholesterol and TRF length in our study also lends further support to this hypothesis. Interestingly it was recently shown that increased HDL cholesterol and TRF were linked to increased longevity even in animal models [41-43].

The association of increased lipid peroxidation (TBARS) with shorter telomeres in our study may indicate a role for reactive oxygen species in telomere shortening. Schisterman et al. [44] have shown that individuals with coronary heart disease had significantly higher levels of TBARS and lipid peroxidation was found to be the best discriminator when the biomarkers of oxidative stress were evaluated individually. Studies in cultured cells have shown that telomere erosion per replication is inversely related to antioxidant capacity $[4,45,46]$. Inflammation and ROS thus appear to be important factors in the pathobiology of age-related disorders, including Type 2 diabetes [47,48]. As suggested by Furumoto et al. [49] telomere length registers the turnover rate of cells, including WBC, a rate that may be augmented by chronic inflammation, and an increase in the cumulative oxidative stress. We found a good correlation between TBARS and telomere shortening. However, in our multiple linear regression model diabetes was the only significant factor in determining telomere shortening, and addition of TBARS did not affect this relationship. This may be explained by the fact that in diabetes, oxidative stress appears as an early biochemical defect and thus further addition of TBARS into the model only had minimal influence.

In summary, we report that telomere shortening of WBCs is observed in Asian Indian patients with Type 2 diabetes. Oxidative stress could be a common molecular mechanism in which the expression of genes related to glucose metabolism, lipid metabolism and vascular function are modified in subjects with diabetes. As telomere length is also highly heritable [29,50], and probably X-linked in some cases [31], the role of genetic predisposition to shortened telomeres in chronic age-related disorders needs further investigation. Telomeres shorten very slowly with age, raising the exciting possibility that telomere shortening may be a risk marker of diabetes and its vascular complications. Future studies are needed to look at telomere shortening in diabetic micro- and macro-vascular complications, and also into whether the shortening can be reversed, at least in part, by tight control of diabetes.

\section{Acknowledgements}

We thank Dr Deepa Raj, Research Biochemist, MDRF, for her help with the statistic analysis. The field studies [Chennai Urban Rural Epidemiology Study (CURES-12)] were supported by the Chennai Wellingdon Corporation Foundation. This work was also partially supported by the Department of Science and Technology (DST), New Delhi, India.

\section{References}

1 Harley CB. Telomere loss: mitotic clock or genetic time bomb? Mutat Res 1991; 256: 271-282.

2 Olovnikov AM. A theory of margitonomy. J Theor Biol 1973; 41: 181-190.

3 Wellinger RJ, Ethier K, Labrecque P, Zakian VA. Evidence for a new step in telomere maintenance. Cell 1996; 85: 423-433.

4 Von Zglinicki T, Saretzki G, Docke W, Lotze C. Mild hyperoxia shortens telomeres and inhibits proliferation of fibroblasts: a model for senescence? Exp Cell Res 1995; 220: 186-193.

5 Slijepcevic P, Xiao Y, Dominguez I, Natarajan AT. Spontaneous and radiation-induced chromosomal breakage at interstitial telomeric sites. Chromosoma 1996; 104: 596-604.

6 Hall DB, Holmlin RE, Barton JK. Oxidative DNA damage through long-range electron transfer. Nature 1996; 382: 731-735.

7 Henle ES, Han Z, Tang N, Rai P, Luo Y, Linn S. Sequence-specific DNA cleavage by $\mathrm{Fe} 2+-$-mediated fenton reactions has possible biological implications. J Biol Chem 1999; 274: 962-971.

8 Von Zglinicki T. Oxidative stress shortens telomeres. Trends Biochem Sci 2002; 27: 339-344.

9 Samani NJ, Boultby R, Butler RB, Thompson JR, Goodall AH. Telomere shortening in atherosclerosis. Lancet 2001; 358: 472-473.

10 Brouilette S, Singh RK, Thompson JR, Goodall AH, Samani NJ. White cell telomere length and risk of premature myocardial infarction. Arterioscler Thromb Vasc Biol 2003; 23: 842-846.

11 Obana N, Takagi S, Kinouchi Y, Tokita Y, Sekikawa A, Takahashi $\mathrm{S}$ et al. Telomere shortening of peripheral blood mononuclear cells in coronary disease patients with metabolic disorders. Intern Med 2003; 42: 150-153.

12 Nakashima H, Ozono R, Suyama C, Sueda T, Kambe M, Oshima T. Telomere attrition in white blood cell correlating with cardiovascular damage. Hypertens Res 2004; 27: 319-325.

13 Jeanclos E, Krolewski A, Skunick J, Kimura M, Aviv H, Warram JH et al. Shortened telomere length in white blood cells of patients with IDDM. Diabetes 1998; 47: 482-486.

14 Mohan V, Alberti KGMM. Diabetes in the Tropics. International Textbook of Diabetes Mellitus, 2nd edn. John Wiley \& Sons Ltd 1997, 9, 171-187. 
15 Mohan V, Sharp PS, Cloke HR, Burrin JM, Schumer B, Kohner EM. Serum immunoreactive insulin responses to glucose load in Asian Indian and European Type 2 (non-insulin-dependent) diabetic patients and control subjects. Diabetologia 1986; 29: 235-237.

16 Sharp PS, Mohan V, Levy JC, Mather HM, Kohner EM. Insulin resistance in patients of Asian Indian and European origin with noninsulin dependent diabetes. Horm Metab Res 1987; 19: 84-85.

17 Enas EA, Garg A, Davidson MA, Nair VM, Huet BA, Yusuf S. Coronary heart disease and its risk factors in first-generation immigrant Asian Indians to the United States of America. Indian Heart J 1996; 48: 343-353.

18 McKeigue PM, Ferrie JE, Pierpoint T, Marmot MG. Association of early-onset coronary heart disease in South Asian men with glucose intolerance and hyperinsulinemia. Circulation 1993; 87: 152-161.

19 Deepa M, Pradeepa R, Rema M, Mohan A, Deepa R, Shanthirani S, Mohan V. The Chennai Urban Rural Epidemiology Study (CURES) study design and methodology (urban component) (CURES-I). J Assoc Physicians India 2003; 51: 863-870.

20 Rema M, Mohan V, Deepa R, Ravikumar R. Association of carotid intimal medial thickness and arterial stiffness with diabetic retinopathy-The Chennai Urban Rural Epidemiology Study [CURES - 2]. Diabetes Care 2004; 27: 1962-1967.

21 Whiting MJ, Shephard MD, Tallis GA. Measurement of plasma LDL cholesterol in patients with diabetes. Diabetes Care 1997; 20: 12-14.

22 Matthews DR, Hosker JP, Rudenski AS, Naylor BA, Treacher DF, Turner RC. Homeostasis model assessment: insulin resistance and $\beta$ cell function from fasting plasma glucose and insulin concentrations in man. Diabetologia 1985; 28: 412-419.

23 Harley CB, FutcherAB, Greider CW. Telomeres shorten during ageing of human fibroblasts. Nature 1990; 345: 458-460.

24 Yagi K. A simple fluorometric assay for lipoperoxide in blood plasma. Biochem Med 1976; 15: 212-216.

25 Oexie K, Zwirner A. Advanced telomere shortening in respiratory chain disorders. Hum Mol Genet 1997; 6: 905-908.

26 Vaziri H, Schachter F, Uchida I, Wei L, Zhu X, Effros R, Cohen D, Harley CB. Loss of telomeric DNA during aging of normal and trisomy 21 human lymphocytes. Am J Hum Genet 1993; 52: 661667.

27 VonZglinicki T. Role of oxidative stress in telomere length regulation and replicative senescence. Ann NY Acad Sci 2000; 908: 99100 .

28 Tchirkov A, Lansdorp PM. Role of oxidative stress in telomere shortening in cultured fibroblasts from normal individuals and patients with ataxia-telangiectasia. Hum Mol Genet 2003; 12: 227-232.

29 Jeanclos E, Schork NJ, Kyvik KO, Kimura M, Skurnick JH, Aviv A. Telomere length inversely correlates with pulse pressure and is highly familial. Hypertension 2000; 36: 195-200.

30 Benetos A, Okuda K, Lajemi M, Kimura M, Thomas F, Skurnick JH, Labat C, Bean K, Aviv A. Telomere length as an indicator of biologic aging: the gender effect and relation with pulse pressure and pulse wave velocity. Hypertension 2001; 37: 381-385.

31 Nawrot TS, Staessen JA, Gardner JP, Aviv A. Telomere length and possible link to X chromosome. Lancet 2004; 363: 507-510.
32 Chen YF. Sexual dimorphism of hypertension. Curr Opin Nephrol Hypertens 1996; 6: 181-185.

33 Fisher ND, Ferri C, Bellini C, Santucci A, Gleason R, Williams GH, Hollenberg NK, Seely EW. Age, gender, and non-modulation: a sexual dimorphism in essential hypertension. Hypertension 1997; 29: 980-985.

34 Kyo S, Takakura M, Kanaya T. Estrogen activates telomerase. Cancer Res 1999; 59: 5917-5921.

35 Marks JB, Raskin P. Cardiovascular risk in diabetes: a brief review. J Diabetes Complications 2000; 14: 108-115.

36 Portaluppi F, Boari B, Manfredini R. Oxidative stress in essential hypertension. Curr Pharm Des 2004; 10: 1695-1698.

37 Wild S, Roglic G, Green A, Sicree R, King H. Global prevalence of diabetes, estimates for the year 2000 and projections for 2030 . Diabetes Care 2004; 27: 1047-1053.

38 Natoli S, Violi F. Oxidative stress and hypercholesterolemia. Increase of radical hydroxyl in patients with hypercholesterolemia. Cardiologia 1999; 44: 187-190.

39 Nourooz-Zadeh J, Rahimi A, Tajaddinin-Sarmadi J. Relationships between plasma measures of oxidative stress and metabolic control in NIDDM. Diabetologia 1997; 40: 647-653.

$40 \mathrm{Xu}$ D, Neville R, Finkel T. Homocysteine accelerates endothelial cell senescence. FEBS Lett 2000; 470: 20-24.

41 Rader DJ. Pathophysiology and management of low high-density lipoprotein cholesterol. Am J Cardiol 1999; 83: 22F-24F.

42 Haussmann MF, Winkler DW, O'Reilly KM, Huntington CE, Nisbet IC, Vleck CM. Telomeres shorten more slowly in long-lived birds and mammals than in short-lived ones. Proc Royal Soc London Biol Sci 2003; 270: 1387-1392.

43 Joeng KS, Song EJ, Lee KJ, Lee J. Long lifespan in worms with long telomeric DNA. Nat Genet 2004; 36: 607-611.

44 Schisterman EF, Faraggi D, Browne R, Freudenheim J, Dorn J, Muti P, Armstrong D, Reiser B, Trevisan M. Minimal and best linear combination of oxidative stress and antioxidant markers to discriminate cardiovascular disease. Nutr Metab Cardiovasc Dis 2002; 12: 259-266.

45 Serra V, VonZglinicki T, Lorenz M, Saretzki G. Extracellular superoxide dismutase is a major antioxidant in human fibroblasts and slow telomere shortening. J Biol Chem 2003; 278: 6824-6830.

46 Kurz DJ, Decary S, Hong Y, Trivier E, Akhmedov A, Erusalimsky JD. Chronic oxidative stress compromises telomere integrity and accelerates the onset of senescence in human endothelial cells. J Cell Sci 2004; 117: 2417-2426.

47 Finkel T, Holbrook NJ. Oxidants, oxidative stress and the biology of aging. Nature 2000; 408: 239-247.

48 Touyz RM. Oxidative stress and vascular damage in hypertension. Curr Hypertension Rep 2000; 2: 98-105.

49 Furumoto K, Inoue E, Nagao N, Hiyama E, Miwa N. Age dependent telomere shortening is slowed down by enrichment of intracellular vitamin C via suppression of oxidative stress. Life Sci 1998; 63: 935948.

50 Slagboom PE, Droog S, Boomsma DI. Genetic determination of telomere size in humans: a twin study of three age groups. Am J Hum Genet 1994; 55: 876-882. 